Dikirim: 17 Januari 2017 Diterbitkan: 1 Juli 2017

\title{
Peran kelas ibu hamil terhadap pemberian ASI Eksklusif di Gunung Kidul
}

The influence of antenatal class implementation toward exclusive breastfeeding in Gunung Kidul

Dwi Andayani ${ }^{1}$, Ova Emilia ${ }^{2}$, Djauhar Ismail ${ }^{1}$

\begin{abstract}
Purpose: This study aimed to determine the effect of the implementation of the antenatal class toward exclusive breastfeeding. Methods: The research was a case-control study with a quantitative approach. This research was also supported by a qualitative approach which aimed to complement and reinforce the results obtained from the quantitative data. Sample cases were 135 exclusive breastfeeding infants aged 6-12 months, and the control sample were 135 not exclusive breastfeeding infants aged 6-12 month. Data analysis used the McNemar and conditional logistic regression tests with significance level of $p=<0.05$ and 95\% confidence interval. Results: Bivariate analysis showed that antenatal class affected exclusive breastfeeding $p=$ 0.026 and $\mathrm{OR}=1.80(95 \% \mathrm{Cl}: 1.03$ to 3.24$)$. In the results of multivariate analysis after controlling by including support of her husband and the ANC $p$ $=0.03$ and $\mathrm{OR}=1.86$ ( $95 \% \mathrm{Cl}: 1.05$ to 3.30). Mothers who attended antenatal class have exclusive breastfeeding rate 1.86 times higher compared to mothers who did not attend the antenatal class. Conclusion: The antenatal class can directly affect exclusive breastfeeding, in spite of controlling the support of her husband and the ANC.
\end{abstract}

Keywords: antenatal class; exclusive breastfeeding

\footnotetext{
${ }^{1}$ Departemen Biostatistik, Epidemiologi, dan Kesehatan Populasi, Fakultas Kedokteran, Universitas Gadjah Mada (Email: dwi.andayani2@gmail.com)

${ }^{2}$ Fakultas Kedokteran, Universitas Gadjah Mada
} 


\section{PENDAHULUAN}

Nutrisi yang adekuat diperlukan untuk memenuhi kebutuhan gizi optimal bayi pada masa pertumbuhan. Global Strategy for infant and Young Child Feeding WHO merekomendasikan 4 hal untuk mencapai tumbuh kembang optimal yaitu dengan pemberian ASI kepada bayi sesegera mungkin 30 menit setelah bayi lahir, memberikan ASI eksklusif sampai bayi berusia 6 bulan, memberikan makanan pendamping ASI (MP-ASI) sejak usia 6 sampai 24 bulan, dan meneruskan pemberian ASI sampai anak berusia 24 bulan atau lebih (1). Pemberian ASI ekslusif selama 6 bulan memiliki berbagai manfaat $(2,3)$.

Pemberian ASI eksklusif merupakan salah satu program yang dicanangkan oleh pemerintah untuk mengurangi kematian bayi. Penelitian epidemiologi menyatakan bahwa ASI dapat melindungi bayi dan anak dari penyakit infeksi, seperti diare, otitis media dan infeksi saluran pernafasan akut bagian bawah. Kolostrum ASI mengandung zat kekebalan 10-17 kali lebih banyak dari susu matang (matur) (4). Berbagai manfaat ASI eksklusif terbukti menurunkan angka kematian bayi dan balita $(5,6)$. Cakupan ASI eksklusif di negara berkembang sangat rendah (39\%) dibandingkan dengan target universal coverage sebesar $90 \%$ (7). Indonesia termasuk 10 besar negara dengan 2/3 bayi yang tidak diberikan ASI eksklusif (5).

Analisis Black et al menunjukkan bahwa praktik pemberian ASI suboptimal, seperti menyusui secara tidak eksklusif berkontribusi 11,6\% terhadap kematian anak di bawah usia 5 tahun (8). Meskipun berbagai program intervensi dikembangkan dalam upaya peningkatan ASI eksklusif seperti konseling laktasi saat Antenatal Care (ANC), kelas ibu hamil, pelaksanaan inisiasi menyusu dini (IMD), kunjungan nifas, serta peraturan perundangan, namun hasil masih jauh dari harapan. Kabupaten Gunung Kidul merupakan salah satu kabupaten yang memiliki cakupan ASI rendah di Yogyakarta. Tahun 2012 dengan cakupan sebesar 44,8\%, tahun 2013 sebesar 56,5\% dan pada tahun 2014 sebesar 59,5\% (9).

Masalah dan komplikasi kehamilan sering dialami ibu. Kelas ibu hamil merupakan salah satu wadah untuk meningkatkan pengetahuan dan keterampilan ibu hamil (10). Masalah pemberian ASI ekslusif menjadi alasan peneliti untuk melakukan penelitian ini. Penelitian ini bertujuan untuk mengetahui pengaruh pelaksanaan kelas ibu hamil terhadap pemberian ASI eksklusif.

\section{METODE}

Penelitian case control dilakukan melibatkan 270 orang ibu yang memiliki bayi berusia 6-12 bulan di Gunung Kidul. Data dikumpulkan secara retrospektif untuk melihat riwayat mengikuti kelas ibu hamil dimasa lalu dengan cara matching, sampel penelitian dikelompokkan menjadi dua yaitu kelompok kasus (ASI eksklusif) dan kelompok kontrol (tidak ASI eksklusif). Subjek kontrol dipilih dari individu dengan kondisi sama dengan subjek kasus. Penelitian ini didukung dengan pendekatan kualitatif yang bertujuan untuk melengkapi dan menguatkan hasil penelitian yang diperoleh dari data kuantitatif.

Variabel bebas adalah variabel yang memengaruhi efek yaitu kelas ibu hamil (KIH), variabel terikat adalah variabel yang dipengaruhi oleh paparan yaitu pemberian ASI eksklusif, dan variabel yang berpotensi sebagai variabel luar dalam penelitian ini adalah pendidikan ibu, pekerjaan ibu, sosial ekonomi, IMD, kunjungan nifas, ANC dan dukungan suami.

\section{HASIL}

Tabel 1 menunjukkan proporsi ibu yang mengikuti kelas ibu hamil lebih banyak pada kelompok kasus daripada kontrol. Ibu bekerja lebih banyak pada kelompok kasus daripada kelompok kontrol.

Tabel 1. Ciri ibu yang memiliki bayi usia 6-12 bulan

\begin{tabular}{|c|c|c|c|c|c|c|}
\hline \multirow{2}{*}{ Variabel } & \multicolumn{2}{|c|}{ Kasus } & \multicolumn{2}{|c|}{ Kontrol } & \multicolumn{2}{|c|}{ Total } \\
\hline & $\bar{n}$ & $\%$ & $\mathbf{n}$ & $\%$ & $\mathbf{N}$ & $\%$ \\
\hline \multicolumn{7}{|l|}{ Kelas ibu hamil } \\
\hline $\begin{array}{l}\text { Mengikuti kelas ibu } \\
\text { hamil }\end{array}$ & 71 & 52,5 & 54 & 40,0 & 125 & 46,3 \\
\hline $\begin{array}{l}\text { Tidak mengikuti kelas } \\
\text { ibu hamil }\end{array}$ & 64 & 47,41 & 81 & 60,0 & 145 & 53,7 \\
\hline \multicolumn{7}{|l|}{ Pendidikan ibu } \\
\hline Rendah & 88 & 65,1 & 84 & 62,2 & 172 & 63,7 \\
\hline Tinggi & 47 & 34,8 & 51 & 37,7 & 98 & 36,3 \\
\hline \multicolumn{7}{|l|}{ Pekerjaan } \\
\hline Bekerja & 40 & 29,6 & 38 & 28,1 & 78 & 28,8 \\
\hline Tidak bekerja & 95 & 70,37 & 97 & 71,8 & 192 & 71,1 \\
\hline \multicolumn{7}{|l|}{ IMD } \\
\hline $\mathrm{Ya}$ & 76 & 56,3 & 82 & 60,7 & 158 & 58,5 \\
\hline Tidak & 59 & 43,7 & 53 & 39,2 & 112 & 41,4 \\
\hline \multicolumn{7}{|l|}{ Kunjungan nifas } \\
\hline $\mathrm{Ya}$ & 78 & 57,7 & 77 & 57,0 & 155 & 57,4 \\
\hline Tidak & 57 & 42,2 & 58 & 42,9 & 115 & 42,5 \\
\hline \multicolumn{7}{|l|}{ Dukungan suami } \\
\hline Dukungan dari suami & 99 & 73,33 & 62 & 45,9 & 172 & 63,7 \\
\hline $\begin{array}{l}\text { Dukungan bukan dari } \\
\text { suami } \\
\text { ANC }\end{array}$ & 36 & 26,6 & 73 & 54,0 & 98 & 36,3 \\
\hline $\mathrm{Ya}$ & 120 & 88,8 & 126 & 93,3 & 246 & 91,1 \\
\hline Tidak & 15 & 11,1 & 9 & 6,6 & 24 & 8,8 \\
\hline \multicolumn{7}{|l|}{ Sosial ekonomi } \\
\hline Kaya & 44 & 32,5 & 45 & 33,3 & 89 & 32,9 \\
\hline Miskin & 91 & 67,4 & 90 & 66,6 & 181 & 67,0 \\
\hline
\end{tabular}


Tabel 2 menunjukkan hubungan pendidikan ibu, pekerjaan ibu, IMD, kunjungan nifas, ANC dan sosial ekonomi dengan pemberian ASI eksklusif, sedangkan dukungan suami mempunyai hubungan bermakna dengan pemberian ASI eksklusif dengan melihat nilai $\mathrm{p}$ $=0,001$ dan OR = 2,44 (95\% CI: 1,38-4,49 bahwa ibu yang mendapatkan dukungan suami berpeluang 2,44 kali lebih tinggi memberikan ASI eksklusif dibandingkan dengan ibu yang tidak mendapatkan dukungan suami.

Tabel 2. Analisis McNemar penyetaraan tempat tinggal terhadap kelas ibu hamil dengan pemberian ASI eksklusif

\begin{tabular}{|c|c|c|c|c|c|c|c|}
\hline \multirow[b]{2}{*}{$\begin{array}{c}\text { Kasus } \\
\text { Kelas ibu hamil }\end{array}$} & \multicolumn{2}{|c|}{ Kontrol kelas ibu hamil } & \multirow[b]{2}{*}{ \% diskosdarn } & \multirow[b]{2}{*}{$\mathbf{X}^{2}$} & \multirow[b]{2}{*}{$\mathbf{P}$} & \multirow[b]{2}{*}{ OR } & \multirow[b]{2}{*}{$95 \%$ CI } \\
\hline & $\begin{array}{c}\text { Mengikuti kelas ibu } \\
\text { hamil }\end{array}$ & $\begin{array}{c}\text { Tidak mengikuti kelas ibu } \\
\text { hamil }\end{array}$ & & & & & \\
\hline Mengikuti kelas ibu & 33 & 38 & & & & & \\
\hline $\begin{array}{l}\text { Tidak mengikuti kelas } \\
\text { ibu hamil }\end{array}$ & 21 & 43 & 0,43 & 4,90 & $0,026^{*}$ & 1,80 & $1,03-3,24$ \\
\hline
\end{tabular}

Keterangan:*signifikan $(\mathrm{p}<0,05)$

"Iya penting untuk bayi, agar kuat, sehat dan tidak mudah sakit, selain itu banyak saran dan pelajaran perawatan bayi yang diberikan di kelas ibu hamil....” (Informan 94).

"Waktu melahirkan, ASI saya pernah 2 hari tidak keluar. Kemudian mertua berencana memberikan air putih dan susu formula, tapi saya tidak beri, karena ingat waktu kelas ibu hamil pernah diberi tahu kalau bayi baru lahir, tidak apa-apa bila 2 hari tidak disusui. Menurut informasi, ada cadangan makanan” (Informan 11).
“...Ibu-ibu sudah mulai sadar kesehatan. Walaupun tidak semua tapi setidaknya, sebagian ibu-ibu. Dengan mengikuti kelas ibu, ibu-ibu jadi paham pentingnya ASI eksklusif." (Informan 2).

Ibu yang mendapatkan dukungan suami memengaruhi pemberian ASI eksklusif.

"Suami sering mengingtkan untuk memberi ASI ke anak, kalau saya lupa pasti dimarahi suami (Informan 82) “...Suami sering membangunkan kalau saya ketiduran dan belum kasi ASI anak saya...” (Informan 14)

Tabel 3. Penyetaraan tempat tinggal terhadap pendidikan ibu, pekerjaan IMD, kunjungan nifas, dukungan suami, ANC, sosial ekonomi dengan ASI eksklusif

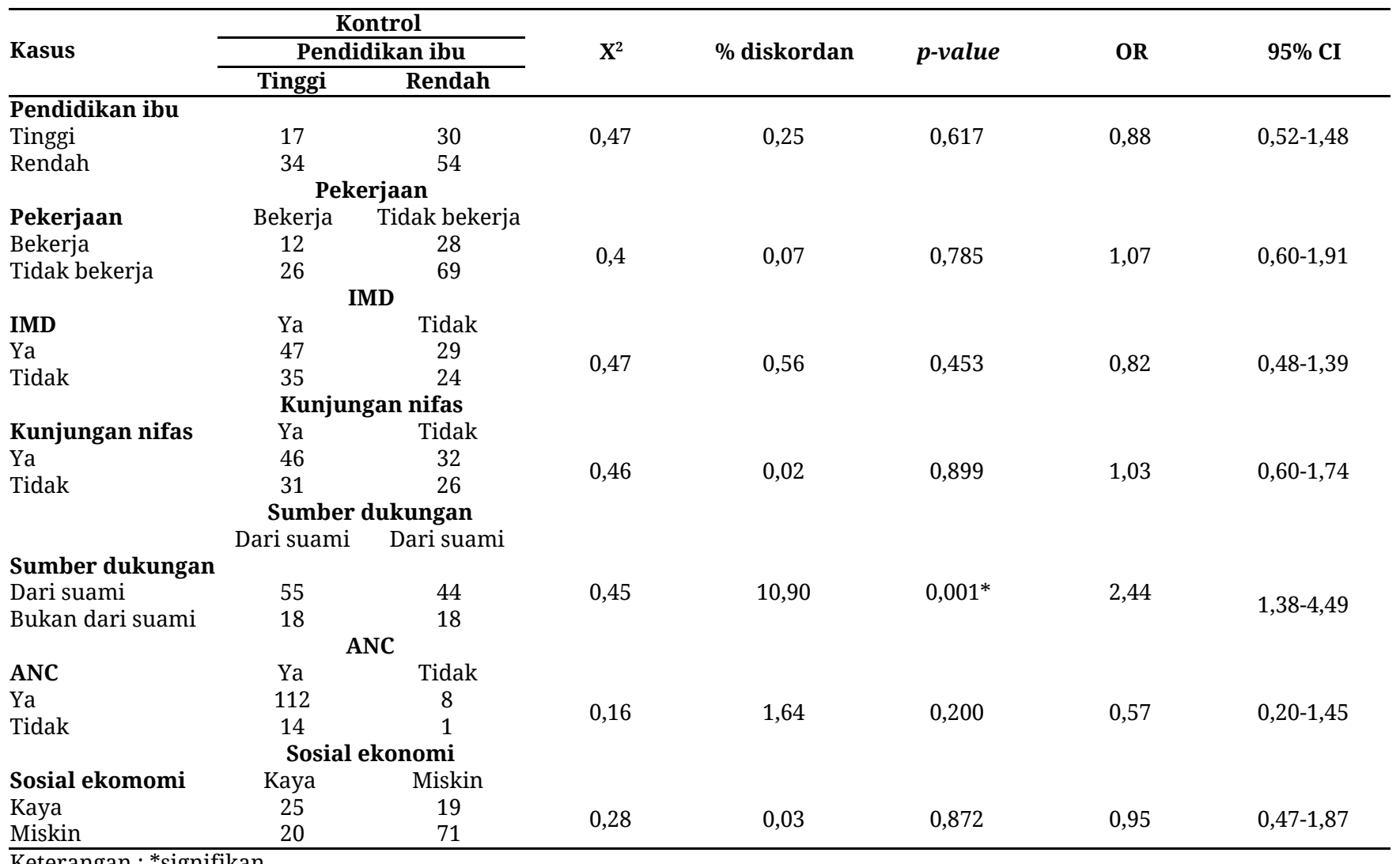

Keterangan : *signifikan 
Model 1 dibangun untuk mengetahui pengaruh variabel kelas ibu hamil terhadap pemberian ASI eksklusif tanpa melibatkan variabel luar. Hasil analisis menunjukkan nilai OR= 1.80 (95\% CI: 1,60-3,08), yang berarti ibu yang mengikuti kelas ibu hamil berpeluang 1.80 kali lebih tinggi dalam pemberian ASI ekslusif dibandingkan dengan ibu yang tidak mengikuti kelas ibu hamil. Model analisis ini menghasilkan nilai R2 $=0,02$, yang berarti bahwa ibu yang mengikuti kelas ibu hamil berkontribusi sebesar $2 \%$ untuk memberikan ASI secara eksklusif sedangkan 98\% merupakan dari faktor lain.

Model 2 dibuat untuk mengetahui pengaruh kelas ibu hamil terhadap pemberian ASI secara eksklusif dengan mengikut sertakan variabel dukungan suami. Hasil analisis chi square menunjukkan adanya persamaan nilai $\mathrm{p}=0,02$ dan kenaikan nilai. Nilai $\mathrm{R} 2=$ 0,09 lebih besar dibandingkan dengan model 1, artinya kelas ibu hamil dan dukungan suami berkontribusi $9 \%$ dalam pemberian ASI eksklusif. Terdapat 91\% faktor lain yang memberikan kontribusi terhadap pemberian ASI secara eksklusif.

Model 3 dibangun dengan tujuan untuk menguji pengaruh kelas ibu hamil terhadap pemberian ASI secara eksklusif dengan mengikut sertakan variabel dukungan suami dan ANC. Hasil analisis menunjukkan nilai $\mathrm{p}=0.03$ dan nilai $\mathrm{O} \mathrm{R}=1,86$ (95\% CI: 1,05-3,30). Nilai R2=0,10 artinya kelas ibu hamil, dukungan suami, dan ANC berkontribusi sebesar 10\% untuk memberikan ASI secara eksklusif.

Tabel 4. Hasil analisis conditional logistic regression kelas ibu hamil dan pemberian ASI eksklusif

\begin{tabular}{|c|c|c|c|}
\hline \multirow{4}{*}{ Variabel } & Model 1 & Model 2 & Model 3 \\
\hline & $\mathbf{P}$ & $\mathbf{P}$ & $\mathbf{P}$ \\
\hline & OR & OR & OR \\
\hline & (CI 95\%) & (CI 95\%) & (CI 95\%) \\
\hline \multicolumn{2}{|l|}{ Kelas ibu hamil } & 0,02 & 0,03 \\
\hline \multicolumn{2}{|l|}{ Mengikuti kelas ibu } & 0,02 & 0,03 \\
\hline hamil & 1,8 & 1,95 & 1,86 \\
\hline $\begin{array}{l}\text { Tidak mengikuti kelas ibu } \\
\text { hamil }\end{array}$ & $(1,60-3,08)$ & $(1,11-3,43)$ & $(1,05-3,30)$ \\
\hline \multicolumn{4}{|l|}{ Sumber dukungan } \\
\hline \multicolumn{2}{|l|}{ Dari suami } & 0,00 & 0,00 \\
\hline \multirow{2}{*}{\multicolumn{2}{|c|}{ Bukan dari suami }} & 2,58 & 2,73 \\
\hline & & $(1,46-4,54)$ & $(1,53-4,87)$ \\
\hline \multicolumn{4}{|l|}{ ANC } \\
\hline \multicolumn{3}{|l|}{$\mathrm{Ya}$} & 0,16 \\
\hline \multirow{2}{*}{\multicolumn{2}{|c|}{ Tidak }} & & 0,51 \\
\hline & & & $(0,20-1,30)$ \\
\hline $\mathbf{N}$ & 270 & 270 & 270 \\
\hline $\mathbf{R}^{2}$ & 0,02 & 0,09 & 0,10 \\
\hline
\end{tabular}

Model 3 dipilih sebagai model terbaik, karena memiliki nilai R2 yang paling besar dan makin banyak variabel yang disandingkan hubungannya tetap signifikan.

\section{BAHASAN}

Penelitian ini menemukan hubungan antara kelas ibu hamil dengan pemberian ASI eksklusif. Ibu yang mengikuti kelas ibu hamil berpeluang 1,80 kali lebih tinggi untuk memberikan ASI eksklusif dibandingkan dengan ibu yang tidak mengikuti kelas ibu hamil. Lumbiganon menyatakan bahwa ibu yang diberi konsultasi ASI, pendidikan menyusui, video menyusui, booklet menyusui dapat meningkatkan pemberian ASI eksklusif sebesar 2,23 kali (11). Program pendidikan pemberian ASI eksklusif sangat efektif meningkatkan pemberian ASI eksklusif di keluarga yang menderita asma, serta dapat membantu ibu menyusui setelah melahirkan caesar $(12,13)$.

Penelitian lain menyatakan bahwa dalam kelas ibu hamil, suami dan istri dipersiapkan untuk menjadi orang tua agar mampu beradaptasi dan melakukan perencanaan dalam kehamilan, selama kelahiran dan periode setelah melahirkan (14). Persiapan pada masa kehamilan berpengaruh terhadap kepuasan setelah bayi lahir. Berbeda dengan ibu yang tidak diberi persiapan dalam masa kehamilan (15).

Kelas ibu hamil memiliki efek positif dari waktu ke waktu mulai dari menyusui, teknik pemberian ASI, persepsi menyusui, waktu tidur bayi setelah menyusui dan dukungan suami pada istri ketika menyusui (15). Hasil penelitian ini sesuai seperti yang diungkapkan oleh informan bahwa yang mengakibatkan ibu memberikan ASI eksklusif adalah ilmu yang didapatkan dalam perawatan kesehatan diri dan bayi, saran yang diberikan dan ibu semakin pintar mengurus anak setelah mengikuti kelas ibu hamil.

Penelitian ini tidak menemukan hubungan antara pendidikan ibu dengan pemberian ASI eksklusif. Ibu berpendidikan sedang sampai tinggi dapat menerima pengetahuan baru dan perubahan dengan baik untuk memelihara kesehatan, terutama tentang ASI eksklusif. Ibu terdorong untuk mencari informasi dan pengalaman, sehingga informasi yang didapat akan menjadi pengetahuan dan akan diterapkan di kehidupan (16).

Penelitian ini hanya mengukur jenjang pendidikan formal ibu dan tidak berdasarkan pengetahuan yang dimiliki ibu. Hal ini didukung oleh penelitian Astuti (17) yang menyatakan bahwa seorang ibu yang berpendidikan rendah memungkinkan mempunyai pengetahuan tinggi tentang praktik pemberian ASI eksklusif dari pendidikan informal. Tingkat pendidikan ibu yang tinggi tidak menjamin seorang ibu memiliki pengetahuan tentang ASI lebih baik (18). Roesli menyatakan bahwa pendidikan mempunyai dampak positif yaitu ibu yang berpendidikan semakin mengerti 
akan pentingnya pemeliharaan kesehatan, termasuk pemberian ASI eksklusif (19). Tetapi pendidikan berdampak negatif, semakin tinggi pendidikan ibu berdampak pada perubahan nilai sosial seperti anggapan bahwa menyusui bayi dianggap tidak modern dan memengaruhi bentuk payudara ibu.

Tingkat pendidikan merupakan salah satu aspek sosial yang berpengaruh pada tingkat pendapatan keluarga sebagai faktor ekonomi. Pendidikan dalam juga memengaruhi sikap dan tingkah laku manusia. Ibu yang berpendidikan tinggi umumnya memiliki kesibukan lain, sehingga cenderung meninggalkan bayi di rumah. Sedangkan ibu yang berpendidikan rendah mempunyai banyak kesempatan untuk menyusui bayi (20). Penelitian yang dilakukan oleh Taveras et al bertolak belakang dengan penelitian ini, yang menyatakan bahwa semakin tinggi tingkat pendidikan ibu, akan semakin tinggi pemberian ASI eksklusif (21).

Status pekerjaan ibu bukan merupakan faktor yang berpengaruh pada pemberian ASI eksklusif. Ibu yang bekerja dan tidak bekerja memiliki tingkat pengetahuan yang cukup baik mengenai pemberian ASI eksklusif. Pengetahuan yang baik memudahkan seseorang dalam merubah perilaku termasuk dalam praktik menyusui (18). Sebagian besar subjek penelitian merupakan ibu rumah tangga yang tidak bekerja. Penelitian Sriningsih menyatakan bahwa tidak berhubungan antara jenis pekerjaan (bekerja dan tidak bekerja) dengan pemberian ASI eksklusif (18).

Pasal 83 UU No. 13 tahun 2003 mengenai ketenagakerjaan menyatakaan bahwa pekerja atau buruh perempuan yang memiliki anak masih menyusu harus diberikan kesempatan untuk menyusui, meskipun dilakukan selama waktu kerja. Kesempatan yang dimaksud merupakan waktu yang diberikan kepada pekerja untuk menyusui, serta tersedia tempat yang sesuai untuk melakukan kegiatan tersebut. Namun undang-undang tersebut belum didukung peraturan daerah mengenai pelaksanaan PP-ASI (22).

Bayi yang diberi kesempatan IMD memiliki kemungkinan lebih besar untuk dapat menyusu ASI secara eksklusif dibandingkan dengan bayi yang tidak diberi kesempatan IMD $(23,24)$. Satu jam pertama merupakan suatu periode emas yang menentukan keberhasilan seorang bayi untuk menyusu secara optimal. Jika 1 jam pertama setelah kelahiran bayi diberi kesempatan menyusu pertama kali, maka akan membangun reflek menghisap yang baik pada bayi. Payudara akan terangsang oleh isapan bayi, otak akan mengeluarkan hormon oksitosin selain hormon prolaktin. Hormon oksitosin, di payudara merangsang sel-sel otot untuk berkontraksi, ASI terdorong mengalir melalui pemuluh darah karena adanya kontraksi. ASI yang diproduksi berdasarkan kebutuhan, jika ASI diambil banyak akan diberikan banyak, yaitu semakin sering diisap bayi, akan semakin banyak ASI yang diproduksi. Tetapi jika bayi berhenti menyusu, maka payudara akan berhenti memproduksi ASI (19).

Penelitian ini tidak menemukan hubungan IMD tdengan pemberian ASI eksklusif. Hasil penelitian ini didukung oleh hasil penelitian yang dilakukan sebelumnya (25) menyatakan bahwa peran petugas kesehatan yang rendah dalam memberikan informasi tentang menyusui maupun pemberian ASI segera setelah melahirkan. Dalam penelitian ini, para ibu yang melakukan IMD maupun tidak melakukan IMD cenderung memberikan ASI eksklusif. Hal ini kemungkinan terjadi karena para ibu mendapatkan dukungan dari keluarga. Sebagian besar ibu dari kelompok kasus mendapatkan dukungan dari suami untuk memberikan ASI eksklusif. Lingkungan rumah terutama peran keluarga dalam mendukung ibu agar tetap dapat memberikan ASI sampai usia bayi 6 bulan sangat penting, sehingga program ASI eksklusif pemerintah bisa lebih berhasil (26.)

Hasil penelitian Susanti menyatakan bahwa terdapat hubungan antara kunjungan masa nifas dengan pemberian ASI eksklusif (27). Berbeda dengan penelitian ini yang menjukkan bahwa tidak ada hubungan antara kunjungan nifas dengan pemberian ASI eksklusif. Hal ini mungkin dikarenakan dalam penelitian ini sebagian besar responden mendapatkan dukungan ketika menyusui. Ibu yang mendapatkan dukungan pada masa nifas cenderung memberikan ASI eksklusif dari pada ibu yang diberikan pendidikan sebelum melahirkan (28).

Dukungan bidan pada masa nifas sebagai promotor hubungan erat antara ibu dan bayi secara fisik dan psikologis. Bidan mengkondisikan ibu untuk menyusui bayi dengan cara meningkatkan rasa nyaman pada masa nifas (31). Petugas kesehatan berkewajiban mendukung ibu ketika melakukan kunjungan nifas, mendukung untuk memberikan ASI pertama kali pada bayi, memastikan ibu untuk dapat menyusui bayi dengan baik dan melakukan penyuluhan kesehatan tentang pemberian ASI eksklusif yang merupakan proses untuk mempertahankan (27).

Penelitian ini menemukan hubungan antara dukungan suami dengan pemberian ASI eksklusif. Ibu yang mendapatkan dukungan dari suami berpeluang 2,44 kali lebih besar untuk memberikan ASI eksklusif dibandingkan dengan ibu yang tidak mendapatkan dukungan dari suami. Penelitian Safiera menyatakan bahwa ada hubungan antara dukungan suami dengan 
minat ibu dalam memberikan ASI eksklusif (29). Keterlibatan suami dalam mendukung istrinya dalam menyusui dapat lebih meningkatkan kenyamanan ibu dalam menyusui daripada keterlibatan petugas kesehatan (30). Informan dalam penelitian menyatakan bahwa suami mendukung ibu dalam menyusui bayi, dengan mengingatkan untuk memberikan ASI. Peran suami dalam pemberian ASI eksklusif sangat penting, untuk meningkatkan kepercayaan diri ibu dan memicu peningkatan produksi ASI.

Penelitian Wahyuningsih (31) menyatakan bahwa ibu yang memberikan ASI eksklusif mayoritas telah menerima dukungan informasi dari suami. Dukungan informasi, dan keluarga berguna sebagai sebuah kolektor dan diseminator (penyebar) informasi mengenai dunia luar. Suami sebagai kepala keluarga dapat memberikan informasi yang dapat digunakan untuk mengungkapkan masalah. Aspek dukungan yang diberikan adalah nasihat, usulan, saran, petunjuk, dan pemberian informasi (31).

ANC (antenatal care) merupakan pemeriksaan kehamilan yang dilakukan ibu selama masa kehamilan di bidan atau dokter untuk mengoptimalisasikan kesehatan mental dan fisik ibu hamil. Ibu diharapkan mampu menghadapi persalinan, nifas, persiapan memberikan ASI (32). Penelitian lain menemukan hubungan kunjungan kehamilan (ANC) dengan pemberian ASI eksklusif (27). Hasil penelitian ini berbeda dengan penelitian lain yaitu tidak ada hubungan antara riwayat ANC dengan pemberian ASI eksklusif. Mayoritas ibu telah mengikuti ANC dengan frekuensi lebih dari 4 kali walaupun tidak memberikan ASI eksklusif.

Keteraturan kunjungan antenatal memengaruhi teknik menyusui yang benar pada ibu nifas dibandingkan dengan kunjungan antenatal yang tidak rutin (33). Kunjungan ANC lengkap dapat memengaruhi kondisi kesehatan ibu dan janin karena ibu mendapatkan kelengkapan informasi serta kondisi ibu dan janin dapat terkontrol dengan baik. Penelitian Agho et al menyatakan bahwa pemberian ASI eksklusif di Nigeria lebih dipengaruhi oleh kunjungan ibu hamil ke unit pelayanan kesehatan selama hamil, pendampingan tenaga kesehatan seperti dokter dan bidan, serta tempat persalinan (34). Ibu yang melakukan kunjungan antenatal 4 kali atau lebih secara signifikan mempunyai kemungkinan memberikan ASI eksklusif.

Tingkat ekonomi keluarga merupakan salah satu faktor yang menentukan pola pemberian ASI. Ibu yang memiliki sosial ekonomi rendah berpeluang 4,6 kali untuk memberikan ASI dibandingkan dengan ibu dengan sosial ekonomi yang tinggi (35). Pada penelitian ini, sosial ekonomi yang diukur adalah tingkat kesejahteraan keluarga berdasarkan tempat tinggal dan kepemilikan barang. Sosial ekonomi tidak berhubungan dengan pemberian ASI eksklusif. Hasil ini sama dengan penelitian Heather et al, Marques et al, Fahriani bahwa tingkat sosial ekonomi tidak memengaruhi pemberian ASI eksklusif (36-38).

Pada hasil penelitian ini, ibu yang memberikan ASI eksklusif sebagian besar adalah responden yang memiliki status ekonomi miskin. Responden memberikan ASI eksklusif pada bayi karena sebagian besar ibu tidak bekerja sebanyak, sehingga memiliki cukup waktu untuk memberikan ASI secara eksklusif. Bekerja menuntut ibu untuk meninggalkan bayi pada usia dini dalam jangka waktu yang cukup lama dalam setiap harinya (39). Lama waktu pisah dengan bayi berpengaruh yang negatif terhadap kelangsungan pemberian ASI. Partisipasi wanita yang meningkat dalam angkatan kerja serta cuti yang kurang memadai bagi para ibu yang bekerja menyebabkan turunnya ketersediaan menyusui dan lama menyusui.

Keluarga dengan latar belakang ekonomi menengah ke bawah cenderung memberikan ASI pada bayinya karena tidak perlu mengeluarkan banyak biaya dan dapat menghemat pengeluaran keluarga (40). Semakin tinggi pengeluaran per kapita rumah tangga, semakin menurun pemberian ASI eksklusif. Faktor pendapatan sangat mendukung pemberian ASI eksklusif (41). Keluarga dengan pendapatan yang rendah cenderung melakukan pemberian ASI eksklusif. Sebagian kecil responden memberikan ASI eksklusif, dikarenakan ibu dengan status ekonomi tinggi memiliki pendidikan tinggi. Ibu berpendidikan tinggi pada umumnya akan semakin mudah untuk menerima informasi, sehingga cenderung mempunyai tingkat pengetahuan ASI eksklusif yang baik (43).

\section{SIMPULAN}

Berdasarkan hasil analisis dan pembahasan penelitian ini maka dapat diperoleh kesimpulan bahwa kelas ibu hamil mempunyai pengaruh yang bermakna terhadap pemberian ASI eksklusif. Pemberian ASI eksklusif tidak hanya dipengaruhi oleh kelas ibu hamil saja, tetapi juga dipengaruhi oleh dukungan suami.

Saran pada penelitian adalah dilakukannya sosialisasi lebih lanjut mengenai pemberian ASI eksklusif sampai kepada suami dan keluarga dengan bantuan kader posyandu yang telah terlatih, sehingga dapat memberikan motivasi dan berperan besar dalam meningkatkan pemberian ASI eksklusif. Petugas puskesmas dengan dibantu kader posyandu 
melakukan pemantauan pemberian ASI eksklusif ke masyarakat yang memiliki bayi. Serta meningkatkan sosialisasi dan promosi mengenai keberadaan kelas ibu hamil (KIH) agar semua ibu mendapatkan informasi bahwa telah terdapat sarana belajar seputar kehamilan, melahir- kan, perawatan ibu dan bayi serta di dalamnya terdapat pelajaran tentang pemberian ASI eksklusif, dan IMD.

\section{Abstrak \\ Tujuan: Penelitian ini bertujuan untuk mengetahui pengaruh pelaksanaan kelas ibu hamil terhadap pemberian ASI eksklusif. Metode: Jenis penelitian observasional dengan rancangan case-control study dengan pendekatan kuantitatif. Penelitian ini juga didukung dengan pendekatan kualitatif yang bertujuan untuk melengkapi dan menguatkan hasil yang diperoleh dari data kuantitatif. Sampel kasus adalah ASI eksklusif pada bayi usia 6-12 bulan, sampel kontrol adalah tidak ASI eksklusif pada bayi usia 6-12 bulan. Total sampel 270 yaitu 135 kasus dan 135 kontrol. Analisis data menggunakan uji McNemar dan conditional logistic regression dengan tingkat kemaknaan $p<0,05$ dan interval kepercayaan 95\%. Hasil: Analisis bivariat menunjukkan bahwa kelas ibu hamil dapat memengaruhi pemberian ASI eksklusif $\mathrm{p}=0,026$ dan OR = 1,80 (95\% CI:1,03- 3,24). Pada hasil analisis multivariabel setelah dilakukan pengontrolan dengan memasukan dukungan suami dan ANC (antenatal care) didapatkan hasil menjadi $\mathrm{p}$ $=0,03$ dan OR = 1,86 (95\% CI:1,05-3,30). Ibu yang mengikuti kelas ibu hamil, tingkat pemberian ASI eksklusif lebih tinggi 1,86 kali dibandingkan dengan ibu yang tidak mengikuti kelas ibu hamil. Simpulan: Secara langsung kelas ibu hamil dapat memengaruhi pemberian ASI eksklusif, meskipun telah dilakukan pengontrolan terhadap dukungan suami dan ANC.}

Kata Kunci: kelas ibu hamil; ASI eksklusif

\section{PUSTAKA}

1. World Health Organization, UNICEF.. Global strategy for infant and young child feeding. World Health Organization; 2003.

2. Kramer MS, Kakuma R. Optimal duration of exclusive breastfeeding. The Cochrane Library. 2012 Aug 15.

3. Horta BL, Bahl R, Martínez JC, Victoria CG. Evidence on the long-term effects of breastfeeding: systematic review and metal-analyses. InEvidence on the long-term effects of breastfeeding: systematic review and metal-analyses 2007. OMS.
4. Kementerian Kesehatan RI. Profil kesehatan Indonesia tahun 2013. Jakarta: Kementerian Kesehatan RI. 2014.

5. UNICEF. Breastfeeding on the worldwide agenda. New York: New York United Nations Children's Fund. 2013.

6. Bhutta ZA, Das JK, Rizvi A, Gaffey MF, Walker N, Horton S, Webb P, Lartey A, Black RE. Evidence-based interventions for improvement of maternal and child nutrition: what can be done and at what cost?. The lancet. 2013 Aug 3;382(9890):452-77.

7. Cai X, Wardlaw T, Brown DW. Global trends in exclusive breastfeeding. International breastfeeding journal. 2012 Dec ;7(1):12.

8. Black RE, Victora CG, Walker SP, Bhutta ZA, Christian $\mathrm{P}$, De Onis M, Ezzati M, Grantham-McGregor S, Katz J, Martorell R, Uauy R. Maternal and child undernutrition and overweight in low-income and middle-income countries. The lancet. 2013 Aug 3;382(9890):427-51.

9. Dinkes Profil Kesehatan Kabupaten Gunung Kidul 2014, Kabupaten Gunung Kidul: Dinas Kesehatan.2015.

10. Kemenkes. Pedoman Pelaksanaan Kelas Ibu Hamil, Jakarta:Kementerian Kesehatan RI. 2011.

11. Lumbiganon P, Martis R, Laopaiboon M, Festin MR, Ho JJ, Hakimi M. Antenatal breastfeeding education for increasing breastfeeding duration. Cochrane Database Syst Rev. 2012 Jan 1;9.

12. Gijsbers B, Mesters I, Knottnerus JA, Kester AD, Schayck CP. The success of an educational program to promote exclusive breastfeeding for 6 months in families with a history of asthma: A randomized controlled trial. Pediatric Asthma, Allergy \& Immunology. 2006 Dec 1;19(4):214-22.

13. Lin $\mathrm{CH}$, Kuo SC, Lin KC, Chang TY. Evaluating effects of a prenatal breastfeeding education programme on women with caesarean delivery in Taiwan. Journal of clinical nursing. 2008 Nov 1;17(21):2838-45.

14. Mete S, Yenal K, Okumuș $\mathrm{H}$. An investigation into breastfeeding characteristics of mothers attending childbirth education classes. Asian nursing research. 2010 Dec 1;4(4):216-26.

15. Goulet L, Fall A, D'Amour D, Pineault R. Preparation for discharge, maternal satisfaction, and newborn readmission for jaundice: Comparing postpartum models of care. Birth. 2007 Jun 1;34(2):131-9.

16. Notoatmodjo, S. (2010). Metodologi Penelitian Kesehatan. Jakarta: PT Rineka Cipta.

17. Astuti, A. T. Pemberian Asi Eksklusif Pada Bayi Usia 0-6 Bulan Di Kabupaten Timor Tengah Selatan Provinsi Nusa Tenggara Timur. Tesis. Universitas Gadjah Mada. 2015.

18. Sriningsih I. Faktor demografi, pengetahuan ibu tentang Air Susu Ibu dan pemberian ASI eksklusif. Jurnal Kesehatan Masyarakat. 2011;6(2).

19. Utami Roesli DR. Mengenal ASI Eksklusif. Penerbit Tubulus Agriwidya. 2000.

20. Depkes. Strategi Nasional Peningkatan Pemberian ASI (PP-ASI). Jakarta: Departemen Kesehatan Republik Indonesia. 2001.

21. Taveras EM, Capra AM, Braveman PA, Jensvold NG, Escobar GJ, Lieu TA. Clinician support and psychosocial risk factors associated with 
breastfeeding discontinuation. Pediatrics. $2003 \mathrm{Jul}$ 1;112(1):108-15.

22. Badan Pusat Statistik. Survey Demografi dan Kesehatan Indonesia. Jakarta. 2012.

23. Chien LY, Tai CJ. Effect of delivery method and timing of breastfeeding initiation on breastfeeding outcomes in Taiwan. Birth. 2007 Jun 1;34(2):123-30.

24. Susilawati. Pengaruh Inisiasi Menyusui Dini (IMD) terhadap kelangsungan pemberian ASI eksklusif di Kabupaten Kampar Riau. Tesis. Yogyakarta: Universitas Gadjah Mada. 2010.

25. Agam I. Faktor-faktor yang Mempengaruhi Pemberian Asi Eksklusif di Kelurahan Tamamaung Kecamatan Pamak Kukang Makasar. Makasar: Fakultas Kesehatan Masyarakat UNHAS. 2011.

26. Hector D, King L, Webb K, Heywood P. Factors affecting breastfeeding practices. Applying a conceptual framework. New South Wales public health bulletin. 2005;16(4):52-5.

27. Susanti dan Rustam. Hubungan Kehamilan dan Kunjungan Nifas Dengan Pemberian ASI Eksklusif Pada Bayi Usia 0-6 Bulan. Jurnal Poltekes Kemenkes. Padang. 2015.

28. Su LL, Chong YS, Chan YH, Chan YS, Fok D, Tun KT, Ng FS, Rauff M. Antenatal education and postnatal support strategies for improving rates of exclusive breast feeding: randomised controlled trial. Bmj. 2007 Sep 20;335(7620):596.

29. Safiera, F. Hubungan Dukungan Suami Terhadap Minat Ibu DDalam Memberikan ASI Eksklusif Di Posyandu Wilayah Puuskesmas Godean II. Fakultas Kebidanan. Universitas Gadjah Mada. 2016.

30. Meedya S, Fahy K, Kable A. Factors that positively influence breastfeeding duration to 6 months: a literature review. Women and Birth. 2010 Dec 1;23(4):135-45.

31. Wahyuningsih D. Dukungan Suami dalam Pemberian ASI Eksklusif. Jurnal Keperawatan Maternitas. 2013;1(2).

32. Saifuddin AB. Buku acuan nasional pelayanan kesehatan maternal dan neonatal. Jakarta: Yayasan Bina Pustaka Sarwono Prawirohardjo. 2006;100:111-2.
33. Aisyah dan Fitriani. Hubungan Antara Keteraturan Kunjungan ANC Dengan Keteranpilan Menyusui Pada Ibu Nifas Diruang Bersalin, Jurnal Midpro. Edisi 1/2013.Universitas Islam Lamongan. 2013.

34. Agho KE, Dibley MJ, Odiase JI, Ogbonmwan SM. Determinants of exclusive breastfeeding in Nigeria. BMC pregnancy and childbirth. 2011 Dec;11(1):2.

35. Purnamawati S. Faktor-faktor yang Berhubungan dengan Pola Pemberian Asi pada Bay1 Usia Empat Bulan (Analisis Data Susenas 2001). Media Penelitian dan Pengembangan Kesehatan. 2003;13(3 Sept).

36. Heather LK, Katie HC, Suzanne CT. Risk Factor For Cessation Of Breastfeeding Prior to Six Month Postpartum a Community Sampel of Woman in Calgary, Alberta. Can J of Pub Health. 2009;6(8):1-4.

37. Marques NM, Lira PI, Lima MC, da Silva NL, Batista Filho M, Huttly SR, Ashworth A. Breastfeeding and early weaning practices in northeast Brazil: a longitudinal study. Pediatrics. 2001 Oct 1;108(4):e66-.

38. Fahriani R, Rohsiswatmo R, Hendarto A. Faktor yang memengaruhi pemberian ASI eksklusif pada bayi cukup bulan yang dilakukan inisiasi menyusu dini (IMD). Sari Pediatri. 2016 Nov 9;15(6):394-402.

39. Indrawati T, Aenti ER. Hubungan Status Pekerjaan Ibu Dengan Pemberian Air Susu Ibu (ASI) Eksklusif pada Bayi Saat Usia 0-6 Bulan di Bidan Praktik Mandiri Kota Semarang. Jurnal Dinamika Kebidanan Akademi Kebidanan Abdi Husada Semarang. 2012;2(2).

40. Riskesdas (2010). Riset Kesehatan Dasar. Badan Penelitian dan Pengembangan Kesehatan. Jakarta: Kementrian Kesehatan RI.

41. Nur Afifah D. Faktor yang Berperan dalam Kegagalan Praktik Pemberian ASI Eksklusif (Studi Kualitatif di Kecamatan Tembalang, Kota Semarang Tahun 2007). SUAR. 2007;3(1).

42. Fatmawati, A.P. Hubungan Status Ekonomi Orangtua Dengan Pemberrian ASI Eksklusif Pada Bayi Usia 0-6 Bulan Di Baki Sukoharjo. Naskah Publikasi. Fakultas Ilmu Kesehattan Universitas Muhammadiyah Surakarta. 2013. 